\title{
Hydropriming Treatment of Rice Seeds With Microbubble Water
}

\author{
Hiromi Ikeura $^{1}$, Fumiyuki Kobayashi ${ }^{2} \&$ Masahiko Tamaki ${ }^{1}$ \\ ${ }^{1}$ School of Agriculture, Meiji University, Kanagawa, Japan \\ ${ }^{2}$ Faculty of Applied Life Science, Nippon Veterinary and Life Science University, Tokyo, Japan \\ Correspondence: Masahiko Tamaki, School of Agriculture, Meiji University, 2060-1, Kurokawa, Asao-ku, \\ Kawasaki, Kanagawa 215-0035, Japan. Tel: 82-44-934-5276. E-mail: mtamaki@meiji.ac.jp
}

Received: January 8, 2014 Accepted: March 20, 2014 Online Published: May 15, 2014

doi:10.5539/jas.v6n6p189 URL: http://dx.doi.org/10.5539/jas.v6n6p189

\begin{abstract}
In rice cultivation, seed emergence and seedling establishment tend to be unstable, and rice plants are likely to lodge during the ripening period in direct seeding, leading to an unsteady yield. Although the possibility of direct seeding in dry paddy fields is being re-examined from the viewpoint of reducing labor, unstable seed emergence and seedling establishment remain as challenges to be dealt with. Therefore, in order to improve unstable seed emergence and seedling establishment, we investigated the effects of hydropriming treatment of rice seeds with microbubble (MB)-water which have effect on promoting plant growth, on emergence and early growth of seedlings. In soil with $50 \%$ moisture content, the emergence rate, seedling height, longest root length, aboveground dry weight, underground dry weight, chlorophyll content, and $\alpha$-amylase activity in seeds primed with MB-water were remarkably higher than those in seeds primed with dechlorinated-water and non-primed seeds. However, no significant differences were observed among the seeds primed the same way in soil with $25 \%$ moisture content. These results demonstrate that the hydropriming treatment of rice seeds with MB-water promotes their emergence in soil with $50 \%$ moisture content. In near future, we need to investigate seedling emergence of other cultivars hydropriming treatment with MB-water.
\end{abstract}

Keywords: emergence, hydropriming, microbubble, rice, priming

\section{Introduction}

In Japan, almost all rice farmers first sow rice seeds in seedling trays so that the seedlings can emerge and grow before they are transplanted in paddy fields. In rice cultivation, sowing rice seeds and planting the seedlings in the paddy fields account for about a quarter of the labor necessary for cultivating rice. Therefore, the introduction of direct seeding of rice in paddy fields is expected to reduce both labor and costs (Furuhata, 2009). However, direct seeding is not popular despite these benefits. Seed emergence and seedling establishment tend to be unstable, and rice plants are likely to lodge during the ripening period in direct seeding, leading to an unsteady yield. Although the possibility of direct seeding in dry paddy fields is being re-examined from the viewpoint of reducing labor, unstable seed emergence and seedling establishment remain as challenges to be dealt with (Ando \& Kobata, 2002).

Seed priming is a technique to promote uniform germination by increasing germination vigor through forced water absorption and drying of seeds. Priming treatment is performed with water-based hydropriming; osmopriming based on high molecular compounds or inorganic salt solution; and matripriming, in which water is supplied via vermiculite and other materials (Horita \& Saruyama, 2006; Farooq et al., 2011). Hydropriming treatment is easy, economical, and environmentally friendly because only water is used. Research on priming treatment with various seeds, including rice seeds, has been reported (Masuda et al., 2005; Horita \& Saruyama, 2006). Ajirloo et al. (2013) evaluated the effects of different seed priming techniques, un-soaked seed (control), hydropriming (soaked with distill water), halopriming with $\mathrm{KNO}_{3}$ and $\mathrm{CaCl}_{2}(1 \%$ solution), on seed emergence and seedling growth of three maize varieties (SC-301, SC-604 and SC-711), and clarified that the response of varieties to different priming techniques approximately was similar and hydropriming gave significantly higher number of leaves compared to other treatments. Hamidreza et al. (2013) conducted to evaluate the effects of different time seed priming (osmo-hydropriming) on germination and seedling growth of Secale montanume seeds under drought conditions, and showed that the least priming time $(6 \mathrm{hr})$ had more effects on germination percentage and the highest root/shoot length ratio was related to osmopriming with $-0.5 \mathrm{MPa}$. Goswami et al. 
(2013) have studied the effects of hydropriming, dehydration priming (induced by PEG), and osmopriming (induced by $\mathrm{NaCl}$ and $\mathrm{KH}_{2} \mathrm{PO}_{4}$ ) on subsequent germination of rice seed (Oryza sativa 'Kshitish'), and showed that germination percentage of hydropriming in water was $92 \%$ and the highest of other treatments. Dey et al. (2013) have also showed that the lowest mean germination time was observed from hydropriming of rice seeds ('BRRI dhan29') with 30 hours soaking at $35^{\circ} \mathrm{C}$.

Thornton and Powell (1992) have reported that germination of Brassica oleracea seeds was improved when aerated water was used in hydropriming treatment. Recently, researchers are interested in using microbubbles $(\mathrm{MBs})$ in the agricultural field since these ultrafine bubbles, which are less than $50 \mu \mathrm{m}$ in diameter, have some unique characteristics (Li et al., 2009a, 2009b; Takahashi et al., 2003; Takahashi, 2005). Promoting the growth of lettuce with air-MBs in hydroponics (Park \& Kurata, 2009) have been reported as applications of MBs in agriculture. Thus, MB treatment for hydropriming of seed may promote seed emergence and early growth of seedling.

This study was performed to investigate the effect of hydropriming treatment of rice seeds with MB-water on the emergence and early growth of seedlings by focusing on the high osmosis of MBs.

\section{Method}

\subsection{Hydropriming Treatment}

In this study, dechlorinated-water was used not only because such water more practical than deionized or distilled water in actual applications but also because the effect of chlorine in tap water must be eliminated. After tap water was aerated for $24 \mathrm{~h}$ at $25^{\circ} \mathrm{C}$, the presence or absence of chlorine in the water was confirmed using a chlorine comparator (Photometer CL, OYWT-31, Oyalox Co., Ltd., Tokyo, Japan) (Ikeura et al., 2011). In the hydropriming treatment with dechlorinated-water, 50 rice seeds of the "Koshihikari" variety were immersed in $30 \mathrm{~L}$ of dechlorinated-water in a plastic container at $25^{\circ} \mathrm{C}$ for $12 \mathrm{~h}$ (dechlorinated-water seeds). 'Koshihikari' account for the greatest proportion of all rice cultivars in Japan (Statistics Agricultura, Foresty and Fishers). In the hydropriming treatment with MB-water, 50 rice seeds were soaked in a similar container of $30 \mathrm{~L}$ of dechlorinated-water for $12 \mathrm{~h}$ after MBs were generated using the MB generation equipment (Royal Electric Co., Ltd., Fukui, Japan) in the container for $15 \mathrm{~min}$ at a flow rate of $2.5 \mathrm{~L} / \mathrm{min}$ (MB-water seeds). After being hydroprimed, the dechlorinated-water seeds and MB-water seeds were dried naturally to a pre-soaking moisture content of $12.6 \%$ in the experiment room. Non-primed seeds were used as the control.

\subsection{Effect of Hydropriming Treatment on the Emergence of Rice Seeds}

Commercial horticultural soil (organic culture soil for flowers and vegetables; Akagi Engei, Isesaki, Gunma, Japan) was first sprayed with dechlorinated-water in order to increase its moisture content. The soil moisture content was adjusted to $50 \%$, which was optimum for the emergence of rice seeds, and $25 \%$, so that emergence is inhibited (Ueyama, 1976). The soil was then put into $400-\mathrm{mL}$ plastic pots where the abovementioned hydroprimed seeds were sown. The pots were covered with a transparent plastic film in order to maintain the moisture levels after the seeds were covered with the soil. Soil moisture content is the volume of water added to soil substances that contribute to the dry weight of the soil. The moisture levels were kept constant during the experiment. An emergence test was performed in a growth chamber (MLR-351H, Sanyo Co., Ltd., Osaka, Japan) under darkness at $30^{\circ} \mathrm{C} / 25^{\circ} \mathrm{C}(12 \mathrm{~h} / 12 \mathrm{~h})$ for 14 days. Emergence was confirmed when a seedling grew $2 \mathrm{~mm}$ or higher from the soil surface. Time taken to reach an emergence ratio of 50\% was indicated as $\mathrm{E}_{50}$ (Farooq et al., 2005). The tests were conducted in triplicate, with 3 plastic pots for each of the 2 types of hydropriming treatments and the control.

\subsection{Effect of Hydropriming Treatment on Growth and Chlorophyll Content}

The commercial horticultural soil was sprayed with dechlorinated-water to increase its moisture content to $25 \%$ or $50 \%$. The soil was then put into $400-\mathrm{mL}$ plastic pots, with 30 seeds sown in each pot after they were hydroprimed in a similar manner as the 50 seeds described above. The seeds were then cultured at $30^{\circ} \mathrm{C} / 25^{\circ} \mathrm{C}$ (12-h bright period and 12-h dark period) with $150 \mu \mathrm{mol} / \mathrm{m} / \mathrm{s}$ of photosynthetic photon flux density at the top of the pots and $80 \%$ relative humidity in a growth chamber for 20 days. Distilled water was sprayed from time to time in order to keep soil moisture content at $25 \%$ or $50 \%$ at $1 \mathrm{~cm}$ below the soil surface. The soil moisture content was constantly monitored using soil moisture censors (ECH2O EC-5, Decagon). One week after sowing, 20 seedlings that had grown relatively uniformly were left in each pot, while the others were eliminated. The test was performed in triplicate, with 3 pots for each of the 2 treatments and the control.

Ten seedlings were randomly chosen from each treatment, and their heights, longest root lengths, aboveground dry weight, and underground dry weight were measured. Chlorophyll content in the aboveground part of the 
remaining seedlings was quantified only in the soil with $50 \%$ moisture content. The fresh aboveground part was dissolved in $80 \%$ acetone, and the absorbance was analyzed using wavelengths of $645 \mathrm{~nm}$ and $663 \mathrm{~nm}$ by using a spectrophotometer (Shimadzu UV-1700, Shimadzu Co., Kyoto, Japan).

\subsection{Effect of Hydropriming Treatment on $\alpha$-Amylase Activity of Brown Rice}

The chaff was removed from hydroprimed brown rice seeds by using tweezers, and the brown rice seeds was crushed and sifted with meshes of $0.5 \mathrm{~mm}$ to extract $\alpha$-amylase by using an $\alpha$-amylase measurement kit (Megazyme International Ireland Ltd., Ireland). The $\alpha$-amylase activity was measured at $400 \mathrm{~nm}$ by using a spectrophotometer (Shimadzu UV-1700).

\subsection{Statistical Analysis}

The experiment was performed 3 times. Statistical differences were analyzed using the least significant difference method at $\mathrm{P}<0.05$.

\section{Results and Discussion}

Table 1 shows the effect of the hydropriming treatments on the emergence ratio of the rice seeds. The emergence ratios of the seeds in the soil with $25 \%$ moisture content were much lower than that of the seeds in the soil with $50 \%$ moisture content. No significant differences existed among the hydropriming treatments and the control in the soil with $25 \%$ moisture content. In the soil with $50 \%$ moisture content, the emergence ratios of the seeds hydroprimed with MB-water were significantly higher than those of the control and dechlorinated-water seeds at any culturing period. In particular, the ratio of the seeds hydroprimed with MB-water on the fifth day of culture was 2.1 times and 1.6 times higher than the ratios of the control and dechlorinated-water seeds, respectively. Moreover, the $\mathrm{E}_{50}$ values of the control, dechlorinated-water seeds, and MB-water seeds were 6.4, 6.3, and 5.6 days, respectively, and a significant difference was observed among the 3 treatments. In addition, the moisture content of rice seeds hydroprimed with the dechlorinated-water and MB-water immediately after water absorption was $23.7 \%$ and $27.7 \%$, respectively (data not shown).

Matsushima and Sakagami (2013) reported that at $8 \%$ soil moisture content, rice seed ('Koshihikari') priming decreased emergence time by $26.8 \mathrm{~h}$ compared with that of the control. Our study showed that hydropriming decreased emergence time $18.2 \mathrm{~h}$ compared with that of the control at $50 \%$ soil moisture content. In addition, Dey et al. (2013) showed that the lowest germination time was observed from hydropriming of seeds ('BRRI dhan29') with $30 \mathrm{~h}$ soaking. These results were not similar to those of their results. It is thought to be factors that constitution in soil, priming temperature, and cultivars that we used differ from those of them. Furthurmore, Himuro (2007) pointed out that MBs probably reduce the surface tension of water by breaking hydrogen bonds among water molecules and promoting the permeability of water molecules. It is supposed that much lower emergence ratios in the soil with $25 \%$ moisture content than in the soil with $50 \%$ moisture content can be attributed to less water absorption by seeds in the soil with $25 \%$ moisture content. Thus, this clearly showed that even the hydropriming treatment of rice seeds with MB-water cannot promote emergence if soil moisture content is not suitable for germination.

These results demonstrated that the hydropriming treatment with MB-water have high effect on the emergence of rice seeds in the soil with $50 \%$ moisture content. It is thought that the ability of rice seeds to absorb moisture may quickly progress because of the remarkably high osmosis of MB-water.

Next, the effect of hydropriming treatment on the early growth of rice seedlings is shown in Table 2. Plant height, longest root length, aboveground dry weight, and underground dry weight of the control, dechlorinated-water, and MB-water seeds in the soil with $25 \%$ moisture content were lower than those of seedlings in the soil with $50 \%$ moisture content. In the soil with $25 \%$ moisture content, no significant differences were observed in growth among the 3 treatments. However, in the soil with 50\% moisture content, plant height, aboveground dry weight, and underground dry weight of the MB-water seeds were higher than those of the dechlorinated-water seeds and control seeds.

Goswami et al. (2013) was reported that shoot and root length priming seeds with water, $\mathrm{KH}_{2} \mathrm{PO}_{4}, \mathrm{NaCl}$ and PEG were about 7-17 cm and 3-7 cm respectively, and higher growth rate than unprimed control seedlings. Dey et al. (2013) showed that shoot and root length when hydropriming treatment was highest germination of rooce seeds were $18.32 \mathrm{~cm}$ and $6.48 \mathrm{~cm}$, respectively. Our result was greater than that of them. Therefore, the hydropriming treatment with MB-water may improve early growth in rice seedlings by promoting emergence.

Finally, in the soil with $50 \%$ moisture content, the effect of the hydropriming treatment on the chlorophyll content of the aboveground part of the seedlings and $\alpha$-amylase activity of brown rice seeds are shown in Table 3. These were measured only in the soil with $50 \%$ moisture content because the effect of the MB-water on the 
emergence ratio and early growth in the soil with $25 \%$ moisture content could not be recognized. The chlorophyll content and $\alpha$-amylase activity in the MB-water seeds were significantly higher than those in the dechlorinated-water seeds and control seeds.

The water content of seeds and chlorophyll amount in cotyledons in Haloxylon persicum could be reduced by salt stress, and this result suggests a correlation between chlorophyll content and seed moisture content (Zhang et al., 2010). Our results are similar to those obtained by Zhang et al. (2010). Therefore, the faster early growth of seedlings in MB-water can probably be explained by a boost in their photosynthesis ability caused by an increase in the chlorophyll content of their cotyledons.

Hydrolysis of starch in rice seeds primed with MB-water might be promoted by improved $\alpha$-amylase activity. Kaur et al. (2002) reported that the $\alpha$-amylase activity of chickpea shoots improved with hydropriming treatment. This finding is consistent with our results. Synthesis of $\alpha$-amylase and other hydrolases in cereal seeds is induced by gibberellins, whose production is initiated by water absorption of seeds (Yoshioka \& Seiwa, 2009). This indicates that $\alpha$-amylase activity in rice seeds is remarkably improved by gibberellin synthesis, which is considerably stimulated by water absorption by rice seeds hydroprimed with highly osmotic MB-water. This result suggests that the growth promotion effect of the hydropriming treatment with MB-water on rice seeds might be attributable to the use of hexose produced by the hydrolysis of starch in the seeds for growing roots and shoots.

Table 1. Effect of hydropriming treatment on emergence ratio of rice seeds

\begin{tabular}{clcccc}
\hline \multirow{2}{*}{ Soil moisture content } & \multirow{2}{*}{ Treatments } & & \multicolumn{2}{c}{ Emergence ratio (\%) } & \multirow{2}{*}{ E $_{50}$} \\
\cline { 3 - 4 } & & & \multicolumn{2}{c}{ Culturing time (days) } & \\
\cline { 3 - 4 } & Control & $0.0 \pm 0.0 \mathrm{a}$ & 4.0 & 14.0 & \\
\hline \multirow{2}{*}{$25 \%$} & Dechlorinated-water & $0.0 \pm 0.0 \mathrm{a}$ & $4.0 \pm 0.6 \mathrm{a}$ & $32.0 \pm 0.4 \mathrm{a}$ & - \\
& MB-water & $0.0 \pm 0.0 \mathrm{a}$ & $4.2 \pm 0.4 \mathrm{a}$ & $32.0 \pm 1.8 \mathrm{a}$ & - \\
\hline \multirow{2}{*}{$50 \%$} & Control & $14.0 \pm 0.4 \mathrm{a}$ & $50.6 \pm 0.6 \mathrm{a}$ & $78.6 \pm 0.4 \mathrm{a}$ & $6.4 \pm 0.1 \mathrm{a}$ \\
& Dechlorinated-water & $18.0 \pm 1.6 \mathrm{a}$ & $51.3 \pm 0.2 \mathrm{a}$ & $79.3 \pm 0.6 \mathrm{a}$ & $6.3 \pm 0.2 \mathrm{a}$ \\
& MB-water & $29.3 \pm 1.2 \mathrm{~b}$ & $64.0 \pm 0.7 \mathrm{~b}$ & $86.0 \pm 0.3 \mathrm{~b}$ & $5.6 \pm 0.1 \mathrm{~b}$ \\
\hline
\end{tabular}

$\mathrm{z}$ Different letters after figures indicate significant differences among treatments at $\mathrm{P}<0.05$.

Table 2. Effect of hydropriming treatment on early growth of rice seedlings

\begin{tabular}{clcccc}
\hline $\begin{array}{c}\text { Soil moisture } \\
\text { content }\end{array}$ & Treatments & $\begin{array}{c}\text { Height } \\
(\mathrm{cm})\end{array}$ & $\begin{array}{c}\text { Longest } \\
\text { root length } \\
(\mathrm{cm})\end{array}$ & $\begin{array}{c}\text { Aboveground } \\
\text { dry weight } \\
(\mathrm{g} / \text { plant })\end{array}$ & $\begin{array}{c}\text { Underground } \\
\text { dry weight } \\
\text { (g/plant })\end{array}$ \\
\hline \multirow{2}{*}{$25 \%$} & Control & $12.5 \pm 0.8 \mathrm{a}^{\mathrm{Z}}$ & $4.5 \pm 0.4 \mathrm{a}$ & $7.1 \pm 0.4 \mathrm{a}$ & $3.9 \pm 0.2 \mathrm{a}$ \\
& Dechlorinated-water & $13.9 \pm 1.5 \mathrm{a}$ & $5.0 \pm 0.3 \mathrm{a}$ & $8.0 \pm 0.4 \mathrm{a}$ & $3.6 \pm 0.3 \mathrm{a}$ \\
& MB-water & $13.4 \pm 1.1 \mathrm{a}$ & $5.2 \pm 0.3 \mathrm{a}$ & $7.9 \pm 0.4 \mathrm{a}$ & $3.8 \pm 0.2 \mathrm{a}$ \\
\hline \multirow{2}{*}{$50 \%$} & Control & $23.9 \pm 1.0 \mathrm{a}$ & $6.4 \pm 0.3 \mathrm{a}$ & $10.2 \pm 0.5 \mathrm{a}$ & $4.2 \pm 0.3 \mathrm{a}$ \\
& Dechlorinated-water & $24.3 \pm 1.5 \mathrm{a}$ & $7.1 \pm 0.4 \mathrm{ab}$ & $10.4 \pm 0.6 \mathrm{a}$ & $4.3 \pm 0.4 \mathrm{a}$ \\
& MB-water & $28.0 \pm 1.0 \mathrm{~b}$ & $7.6 \pm 0.3 \mathrm{~b}$ & $12.6 \pm 0.6 \mathrm{~b}$ & $5.1 \pm 0.2 \mathrm{~b}$ \\
\hline
\end{tabular}

\footnotetext{
${ }^{\mathrm{z}}$ Different letters after figures indicate significant differences among treatments at $\mathrm{P}<0.05$.
} 
Table 3. Effect of hydropriming treatment on chlorophyll content and $\alpha$-amylase activity of brown rice seeds in $50 \%$ soil moisture content

\begin{tabular}{lll}
\hline Treatments & $\begin{array}{l}\text { Chlorophyll content } \\
(\mathrm{mg} / 100 \mathrm{~g})\end{array}$ & $\begin{array}{l}\alpha \text {-amylase activity } \\
\left(\times 10^{-2} \mathrm{Units} / \mathrm{g}\right)\end{array}$ \\
\hline Control & $1.19 \pm 0.08 \mathrm{a}^{\mathrm{Z}}$ & $5.3 \pm 0.5 \mathrm{a}$ \\
Dechlorinated-water & $1.29 \pm 0.06 \mathrm{a}$ & $5.4 \pm 0.4 \mathrm{a}$ \\
MB-water & $1.60 \pm 0.09 \mathrm{~b}$ & $7.0 \pm 0.3 \mathrm{~b}$ \\
\hline
\end{tabular}

${ }^{\mathrm{Z}}$ Different letters after figures indicate significant differences among treatments at $\mathrm{P}<0.05$.

\section{Conclusion}

The experiment was conducted to study the effects of hydropriming treatment of rice seeds 'Koshihikari' with microbubble (MB)-water which have effect on promoting plant growth, on emergence and early growth of seedlings. Hydropriming treatment with MB-water is extremely effective in improving the seedling emergence ratio and in promoting early growth. We believe that MB-water improved the emergence rate and promoted early growth by helping the seeds absorb water efficiently as a result of the considerably high osmosis of MB-water. In near future, we need to investigate seedling emergence of other cultivars hydropriming treatment with MB-water.

\section{References}

Ajirloo, A. R., Shaban, M., \& Moghanloo, G. D. (2013). Effect of priming methods on emergence and seedling growth of maize (Zea mayze L.). International Journal of Farming and Allied Sciences, 2, 658-661.

Ando, H., \& Kobata, T. (2002). Effect of seed hardening emergence and $\alpha$-amylase activity in the grains of wheat and rice sown in dry soil. Japanese Journal of Crop Science, 71, 220-225 (In Japanese with English Abstract). http://dx.doi.org/10.1626/jcs.71.220

Dey, A., Sarkar, M. A. R., Pail, S. K., \& Roy, P. K. (2013). Effect of hydropriming on field establishment of seedlings obtained from primed seeds of boro rice cv. BRRI dhan29. International Journal of Applied Science Biotechnology, 1, 220-223. http://dx.doi.org/10.3126/.ijasbt.v1i4._9102

Farooq, M., Basra, S. M. A., Hafeez, K., \& Ahmad, N. (2005). Thermal hardening: A new seed vigor enhancement tool in rice. Journal of Integrative Plant Biology, 47, 187-193. http://dx.doi.org/10.1111/j.1744-7909.2005.00031.x

Farooq, M., Siddique, K. H. M., Rehman, H., Aziz, T., Lee, D. J., \& Wahid, A. (2011). Rice direct seeding: Experiences, challenges and opportunities. Soil \& Tillage Research, 111, 87-98. http://dx.doi.org/10.1016/j.still.2010.10.008

Furuhata, M. (2009). Improvement of seedling emergence and establishment of rice direct seeded in flooded paddy fields. Japanese Journal of Crop Science, 78, 153-162. http://dx.doi.org/10.1626/jcs.78.153

Goswami, A., Banerjee, R. \& Raha, S. (2013). Drought resistance in rice seedlings conferred by seed priming. Protoplasma, 250, 1115-1129. http://dx.doi.org/10.1007/s00709-013-0487-x

Hamidreza, K., Earl, H., Sabzevari, S., Yanegh, J., \& Bannayan, M. (2013). Effects of osmo-hydropriming and drought stress on seed germination and seedling growth of rye (Secale montanum). ProEnvironment, 6, 496-507.

Himuro, S. (2007). A new washing method using microbubbles. Progress in Multiphase Flow Research, 2 , 39-45 (In Japanese).

Horita, M., \& Saruyama, H. (2006). Acceleration of germination of onion seeds by priming treatment with trehalose and raffinose. Horticultural Research (Japan), 5, 75-78 (In Japanese with English Abstract). http://dx.doi.org/10.2503/hrj.5.75

Ikeura, H., Kobayashi, F., \& Tamaki, M. (2011). Removal of residual pesticide, fenitrothion, in vegetables by using ozone microbubbles generated by different methods. Journal of Food Engineering, 103, 345-349. http://dx.doi.org/10.1016/j.jfoodeng.2010.11.002

Kaur, S., Gupta, A. K., \& Kaur, N. (2002). Effect of osmo- and hydropriming of chickpea seeds on seedling growth and carbohydrate metabolism under water deficit stress. Plant Growth Regulation, 37, 17-22. http://dx.doi.org/10.1023/A:1020310008830 
Li, P., Takahashi, M., \& Chiba, K. (2009a). Enhanced free-radical generation by shrinking microbubbles using a copper catalyst. Chemosphere, 77, 1157-1160. http://dx.doi.org/10.1016/j.chemosphere.2009.07.062

Li, P., Takahashi, M., \& Chiba, K. (2009b). Degradation of phenol by the collapse of microbubbles. Chemosphere, 77, 1371-1375. http://dx.doi.org/10.1016/j.chemosphere.2009.03.031

Masuda, M., Hata, N., Ombwara, F. K., \& Agong, S. G. (2005). Effects of acid scarification, priming with PEG, $\mathrm{NaCl}$ or sea water as osmoticum and dehydration on spinach seed germination at $30^{\circ} \mathrm{C}$. Journal of the Japanese Society for Horticultural Science, 74, 134-138. http://dx.doi.org/10.2503/jjshs.74.134

Matsushima, K., \& Sakagami, J. (2013). Effects of seed hydropriming on germination and seedling vigor during emergence of rice under different soil moisture conditions. American Journal of Plant Sciences, 4, 1584-1593. http://dx.doi.org/10.4236/ajps.2013.48191

Park, J. S., \& Kurata, K. (2009). Application of microbubbles to hydroponics solution promotes lettuce growth. HortTechnology, 19, 212-215.

Statistics Agricultura, Foresty and Fishers. Retrieved from http://www.maff.go.jp/j/tokei/kouhyou/sakumotu/ sakkyou_kome/index.html

Takahashi, M. (2005). $\zeta$ Potential of microbubbles in aqueous solutions: electrical properties of the gas-water interface. Journal of Physical Chemistry B, 109, 21858-21864. http://dx.doi.org/10.1021/jp0445270

Takahashi, M., Kawamura, T., Yamamoto, Y., Ohnari, H., Himuro S., \& Shakutsui, H. (2003). Effect of shrinking microbubble on gas hydrate formation. Journal of Physical Chemistry B, 107, 2171-2173. http://dx.doi.org/10.1021/jp022210z

Thornton, J. M., \& Powell, A. A. (1992). Short-term aerated hydration for the improvement of seed quality in Brassica oleracea. Seed Science Research, 2, 41-49.

Ueyama, Y. (1976). Influence of soil moisture content on seedling emergence and on stimulating effect of seed treatment with gibberellin on seedling emergence in direct seeding culture of paddy rice on upland field. The science reports of Faculty of Agriculture, Kobe University, 12, 5-13 (In Japanese with English Abstract).

Yoshioka, T., \& Seiwa, K. (2009). Seed germination-physiology, ecology and molecular mechanisms. Bun-ichi Sogo Shuppan Co., Tokyo, Japan, 245-250 (Japanese).

Zhang, S., Song, J., Wang, H., \& Feng, G. (2010). Effect of salinity on seed germination, ion content and photosynthesis of cotyledons in halophytes or xerophytes growing in central Asia. Journal of Plant Ecology, 3, 259-267. http://dx.doi.org/10.1093/jpe/rtq005

\section{Copyrights}

Copyright for this article is retained by the author(s), with first publication rights granted to the journal.

This is an open-access article distributed under the terms and conditions of the Creative Commons Attribution license (http://creativecommons.org/licenses/by/3.0/). 